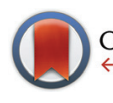

CrossMark \& click for updates

Cite this: Dalton Trans., 2015, 44 11984

Received 22nd April 2015, Accepted 29th May 2015

DOI: 10.1039/c5dt01529d www.rsc.org/dalton

\title{
Photophysical tuning of the aggregation-induced emission of a series of para-substituted aryl bis (imino)acenaphthene zinc complexes $\dagger$
}

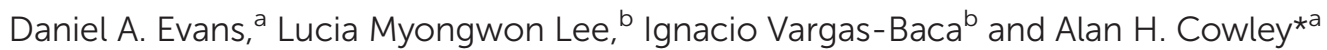 \\ Bis(imino)acenaphthene (BIAN) zinc complexes with para-substituted aryl groups have been synthesized \\ and investigated from the standpoint of their photophysical properties. Each complex was found to be \\ nonemissive in solution. However, complexes 1-6 turned out to be emissive in the solid state, while com- \\ plexes $\mathbf{7}$ and $\mathbf{8}$ remained nonemissive. The emissions for complexes $\mathbf{1 - \mathbf { 8 }}$ displayed color tunability \\ ranging from red-yellow. A detailed crystallographic study of the "as-synthesized" structures revealed \\ a distinct difference in the crystal packing environments of the emissive and nonemissive complexes. \\ Furthermore, a solvatomorphic study provided further emission tunability via changes in the crystal \\ packing environments of each solvatomorph. Lastly, TD-DFT calculations were performed in order to \\ investigate the effect of different para-substituents on the flanking aryl rings of the BIAN ligand.
}

\section{Introduction}

The design and fabrication of organic light emitting diodes (OLEDs) for use in solid state optoelectronic devices is one of the most rapidly advancing fields of current research today. ${ }^{1} \mathrm{~A}$ significant advantage of OLED technologies relates to the facile solution based tunability of the organic emissive layer by means of chemical modification. Moreover, the availability of such chemical modifications of the small molecule organic emissive layer allows for a variety of luminescent properties to be achieved within a single chemical framework, an outcome that is not possible with semiconductor LED materials. The viability of this approach was elegantly demonstrated by Anzenbacher $e t$ al., who succeeded in tuning the emission of the ubiquitous tris(8-quinolinate) $\mathrm{Al}(\mathrm{III})\left(\mathrm{Alq}_{3}\right)$ complex, thereby achieving excellent color tunability that spanned the entire visible spectrum from red to blue emission. ${ }^{2,3}$ The foregoing result was made possible by the installation of electron donating/withdrawing groups in the $\mathrm{C} 5$ position of the quinolinate ligand, thereby permitting manipulation of the HOMO-LUMO gap. In turn, the use of the foregoing chemical modifications resulted in the generation of distinct emissive properties for each $\mathrm{Alq}_{3}$ derivative. Furthermore, photophysical tunability of

\footnotetext{
${ }^{a}$ Department of Chemistry, The University of Texas at Austin, Austin, Texas, USA. E-mail:acowley@cm.utexas.edu

${ }^{b}$ Chemistry \& Chemical Biology, McMaster University, Hamilton, Ontario, Canada $\dagger$ Electronic supplementary information (ESI) available. CCDC 1061236-1061250. For ESI and crystallographic data in CIF or other electronic format see DOI: $10.1039 / \mathrm{c} 5 \mathrm{dt} 01529 \mathrm{~d}$
}

this type has emerged as a viable method for the development of solid state OLED technologies. ${ }^{4,5}$

Although the majority of organic based emissive materials are highly luminescent in solution, they frequently suffer from a dramatic decrease in emission intensity in the solid state, a problem that is typically referred to as aggregation-caused quenching (ACQ). ${ }^{6}$ ACQ is particularly troublesome for the fabrication of solid state optoelectronic devices since the emissive material is typically quenched upon formation of its aggregate state. Fortunately however, Tang et al. discovered the fascinating phenomenon that is now known as aggregationinduced emission (AIE). In turn, AIE has been shown to be a viable option for circumvention of the problems that are typically encountered in the fabrication of solid state emissive materials. ${ }^{7-9}$ As a consequence, the obstacle of ACQ, that heretofore had arrested the development of OLED technologies, could now be overcome by the utilization of AIE materials. Moreover, in a more recent study by Tang et al., the color tunability of pyran based AIE active compounds was achieved by means of similar chemical modifications..$^{10}$ Furthermore, in a related study by Chujo and Kokado, the emissive properties of a diphenyl-o-carborane were manipulated successfully by the installation of electronic donating/withdrawing groups on the periphery of the ligand framework. Additionally, full color emission was achieved by electronic tuning of the diphenyl-o-carborane ligand framework. ${ }^{11}$ Given these promising preliminary results, it seemed clear that the further development of color-tunable AIE compounds could result in significant technological improvements in solid state optoelectronic devices. 
The stereoelectronic tunability and excellent redox properties of the bis(imino)acenaphthene (BIAN) ligand class has rendered such compounds very useful in the contexts of synthetic, structural, and catalytic chemistry. ${ }^{12}$ Interestingly, there are only a few instances in which BIAN ligands have been used for photoluminescent applications. ${ }^{13-16}$ However, in a recently published study from our laboratory, it was reported that the BIAN ligand can be used as a support for AIE materials. ${ }^{17}$ In this particular study, the emissions of a series of methylated aryl substituted BIAN (Ar-BIAN) zinc complexes with flanking p-methylphenyl (4-Me), 3,5-dimethylphenyl (3,5-Me), 2,4,6-trimethylphenyl (Mes), and $o$-methylphenyl (2-Me) substituents were investigated. It was discovered that the emissions from these complexes were quenched in solution and only became emissive in the aggregated state. Furthermore, on the basis structural studies that were supported by subsequent DFT calculations, it became evident that the foregoing emissions resulted from the intramolecular $\pi$-stacking dimeric interactions that were present in the crystal lattices of the para- and meta-substituted complexes. Interestingly however, the orthosubstituted complexes exhibited different packing environments, presumably due to steric effects, and hence did not feature this specific interaction. As a consequence, these complexes were found to be nonemissive in the solid state. (Fig. 1).

The methylated aryl substituents discussed above were selected in order to investigate and thereby determine the origins of the emissions from the BIAN zinc complexes while holding the electronics of each sample constant. Accordingly, the overall objective of the present work was to investigate the effects that electronic and structural modifications could have on the solid state photoluminescent properties of a series of BIAN zinc complexes.

\section{Results and discussion}

\section{Photophysical properties of Ar-BIAN complexes 1-8}

The photoluminescent behavior of a series of methylated ArBIAN zinc(II) chloride complexes has already been explored and reported in a preliminary publication from our labora-

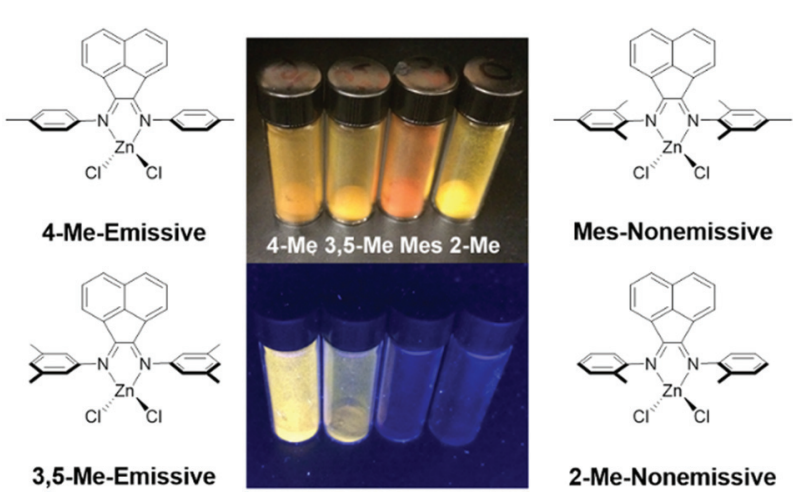

Fig. 1 Emissive behavior of methylated Ar-BIAN zinc(II) chloride complexes. $^{17}$ tory. ${ }^{17}$ Given that the results proved to be interesting, it was decided to expand this study to include a significantly broader series of Ar-BIAN zinc(II) chloride complexes. Accordingly, the present work is focused on tuning of the electronic properties of a series of para-substituted aryl substituents. The electronic series of aryl substituents that were employed in this investigation comprise the 4-butoxy, (4-OBu), 4-methoxy (4-OMe), 4-methylthio (4-SMe), 4-phenoxy (4-OPh), 4-fluoro (4-F), 4-bromo (4-Br), 4-trifluoromethoxy, $\left(4-\mathrm{OCF}_{3}\right)$, and 4-trifluoromethyl $\left(4-\mathrm{CF}_{3}\right)$ substituents. Although the 4 -OMe, ${ }^{18} 4-\mathrm{F},{ }^{19} 4$ $\mathrm{Br},{ }^{20}$ and $4-\mathrm{CF}_{3}{ }^{21}$ BIAN ligands had been synthesized previously, their luminescent properties had not been investigated. Furthermore, in order to broaden the scope of the present study the new 4-OBu, 4-SMe, 4-OPh, and 4-OCF 3 BIAN complexes were synthesized and added to the list of complexes to be examined.

The synthesis of each Ar-BIAN zinc complex was performed by means of a facile condensation reaction, the details of which have already been described in the literature (Scheme 1). ${ }^{22}$ The Ar-BIAN Zn(II) chloride complex was generated as a precipitate that had formed during the condensation reaction in acetic acid. Complexes 1-8 were synthesized in high yields and isolated as dark red to yellow crystalline powders, the photophysical properties of which were subsequently investigated.

Initially, the absorption properties of complexes 1-8 were assessed by means of UV/Vis absorption spectroscopy studies that were carried out in DCM solution (Fig. 2). As displayed in Fig. 2, each spectrum for complexes 1-8 featured similar absorption bands. In accord with previously published BIAN $\mathrm{UV} /$ Vis studies, the high energy bands $(<350 \mathrm{~nm})$ were assigned to $\pi-\pi^{*}$ transitions that stem from both the aryl moieties and the naphthalene backbone. ${ }^{23-25}$ Based on the TD-DFT studies reported by Zysman-Colman et al., ${ }^{26}$ the lower energy bands can be tentatively assigned to intraligand charge transfers (ILCT) that emanate from the flanking aryl substituents and the naphthalene backbone. A summary of the pertinent UV/Vis absorption spectroscopic data is presented in Table 1.

Inspection of the solid state diffuse reflectance spectra for complexes 1-8, revealed that complexes 1-6 exhibited intense broad absorption peaks. On the other hand, complexes 7 and 8 featured less intense blue shifted peaks in comparison with those of complexes 1-6. Each absorption band blue

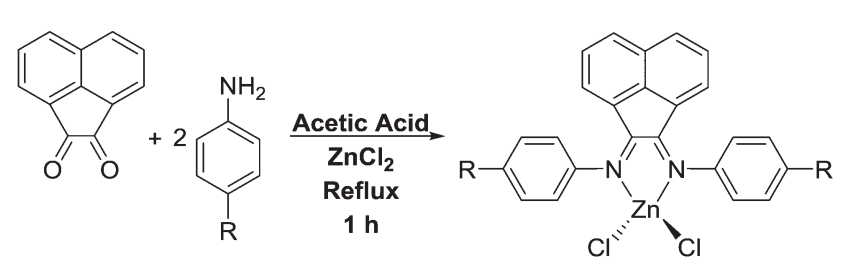

$R=$ butoxy (1), methoxy (2), methylthio (3), phenoxy (4), fluoro (5), bromo (6), trifluoromethoxy (7), trifluoromethyl (8)

Scheme 1 Syntheses of Ar-BIAN zinc chloride complexes 1-8. 


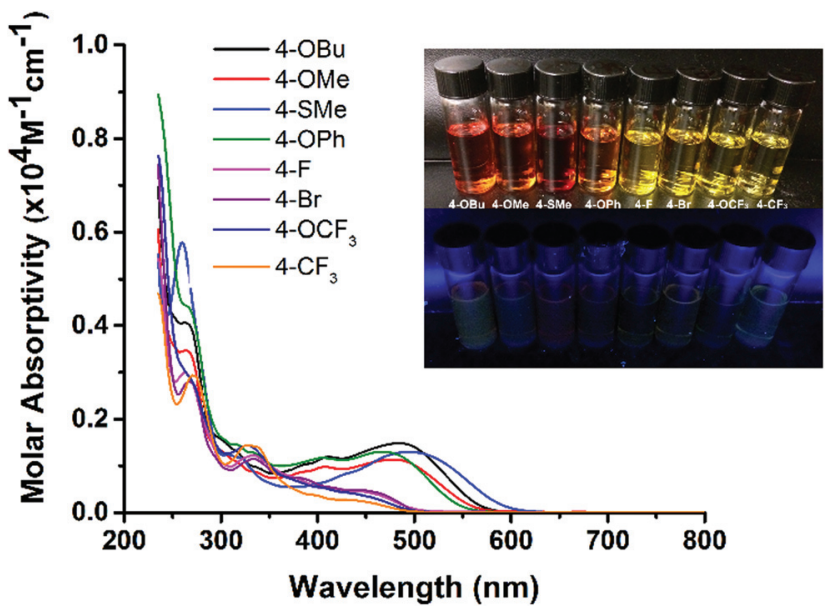

Fig. 2 UV/Vis absorption spectra of 1-8 in DCM solution. A photograph of each solution was taken in both ambient light and also under UV irradiation.

Table 1 Solution based UV/Vis data for complexes 1-8

\begin{tabular}{lll}
\hline Complex & $\lambda_{\max }(\mathrm{nm})$ & $\varepsilon\left(\times 10^{4} \mathrm{M}^{-1} \mathrm{~cm}^{-1}\right)$ \\
\hline $\mathbf{1}$ & $484,411,298 \mathrm{sh}, 262$ & $1.49,1.19,1.60,4.06$ \\
$\mathbf{2}$ & $478,408,315 \mathrm{sh}, 264$ & $1.14,0.98,1.10,3.46$ \\
$\mathbf{3}$ & $495,307,260$ & $1.30,1.24,5.78$ \\
$\mathbf{4}$ & $467,405,315,263 \mathrm{sh}$ & $1.30,1.17,1.46,4.44$ \\
$\mathbf{5}$ & $435,333,263$ & $0.47,1.23,2.99$ \\
$\mathbf{6}$ & $440,333,267$ & $0.49,1.15,2.80$ \\
7 & $428 \mathrm{sh}, 328,263 \mathrm{sh}$ & $0.43,1.44,3.02$ \\
$\mathbf{8}$ & $423 \mathrm{sh}, 327,271$ & $0.28,1.44,2.93$
\end{tabular}

shifted progressively as the electron withdrawing character increased. The sole exception was complex 3 which displayed a significantly red-shifted emission. A summary of the pertinent solid state UV/Vis reflectance spectroscopic data is presented in Table 2.

The next phase of the work was focused on the photoluminescence properties of 1-8. As displayed in Fig. 2, all eight complexes were found to be nonemissive in DCM solution. Interestingly, however, complexes 1-6 turned out to be emissive in the solid state, while complexes $\mathbf{7}$ and $\mathbf{8}$ retained their

Table 2 Solid state diffuse reflectance UV/Vis spectroscopic data for complexes 1-8

\begin{tabular}{|c|c|c|c|}
\hline Complex & $\lambda_{\max }(\mathrm{nm})$ & Intensity (Kubelka-Munk) & $\% \mathrm{w} / \mathrm{w}$ of $\mathrm{BaSO}_{4}$ \\
\hline 1 & 514 & 10.24 & 50 \\
\hline 2 & 517 & 11.36 & 50 \\
\hline 3 & 540 & 13.67 & 50 \\
\hline 4 & 502 & 9.38 & 90 \\
\hline 5 & 501 & 9.34 & 90 \\
\hline 6 & 493 & 7.25 & 90 \\
\hline 7 & 446 & 2.36 & 90 \\
\hline 8 & 452 & 2.79 & 90 \\
\hline
\end{tabular}

nonemissive behavior (Fig. 3). The emissions of complexes 1-6 were identified as being phosphorescent based on their microsecond lifetimes $(\tau)$. Furthermore, the emissions of the foregoing complexes also exhibited relatively low absolute quantum yields $(\Phi)$.

Interestingly, the emissions that were detected for complexes 1-6 exhibited an overall color tunability that changed progressively from red to orange to yellow. This particular tunability was achieved by modification of the electronic properties of the para-substituted aryl substituents. Overall, it was found that electron donating groups such as 4-BuO, 4-MeO, and 4-SMe exhibited emissions in the red region of the spectrum. On the other hand, the 4-OPh and 4-F substituted complexes exhibited orange based emissions. Finally, the 4-Br substituted complex was found to display a yellow based emission.

As evident from Table 3, the emissions for complexes 1-6 followed a general trend, namely that as the electron withdrawing strength of the para-substituted flanking aryl group increased, the emission progressively underwent a blue shift. In order to confirm and quantify this observation, a Hammett relationship was investigated with the objective of determining whether a correlation existed between the $\sigma_{\mathrm{p}}$ and $\lambda_{\max }$ values of the emissions. As displayed in Fig. 3, if the 4-SMe substituted complex $\mathbf{3}$ is omitted from the series, complexes $\mathbf{1}, \mathbf{2 , 4} \mathbf{4}, \mathbf{5}$, and $\mathbf{6}$ were found to exhibit a linear Hammett relationship between the $\sigma_{\mathrm{p}}$ value and the $\lambda_{\max }$ of each emission. This relationship was confirmed on the basis of a Pearson regression value of $R^{2}$ $=0.984$. However, if the 4-SMe substituted complex 3 is included in this series it is clearly an outlier with a new Pearson regression value of $R^{2}=0.486$. Overall, complex 3 exhibited both significantly red shifted absorption and emission peaks with respect to the $\sigma_{\mathrm{p}}$ value when compared with those of the other complexes in this series.

Although the color tunability described above represented an exciting discovery, it became necessary to employ aggregation-induced emission (AIE) experiments in order to gain further insight into the nature of the emissions of all six complexes. With this in mind, each BIAN zinc chloride complex was dissolved in a stock solution of DCM and volumetric fractions were prepared with the non-solvent hexanes. A representative example of an AIE experiment with a DCM solution $\left(\sim 10^{-4} \mathrm{M}\right)$ of $\mathbf{1}$ is presented in Fig. 4. Further details regarding the AIE experiments of $2-6$ can be found in the ESI. $\dagger$

As evident from Fig. 4, the DCM solution of complex 1 was found to be nonemissive in the DCM/hexanes fraction range of 100\% DCM to 50\% DCM : 50\% hexanes. These volumetric fractions were completely translucent. However, upon formation of the 40\% DCM : 60\% hexanes mixture, complex 1 began to precipitate. This particular fraction exhibited a very faint emission as evident from both the photographs and also from the emission spectra that are presented in Fig. 4. However, the emission was found to be intensified in the range of the $30 \%$ DCM : 70\% hexanes to 10\% DCM : 90\% hexanes, at which point the precipitation had increased significantly. 

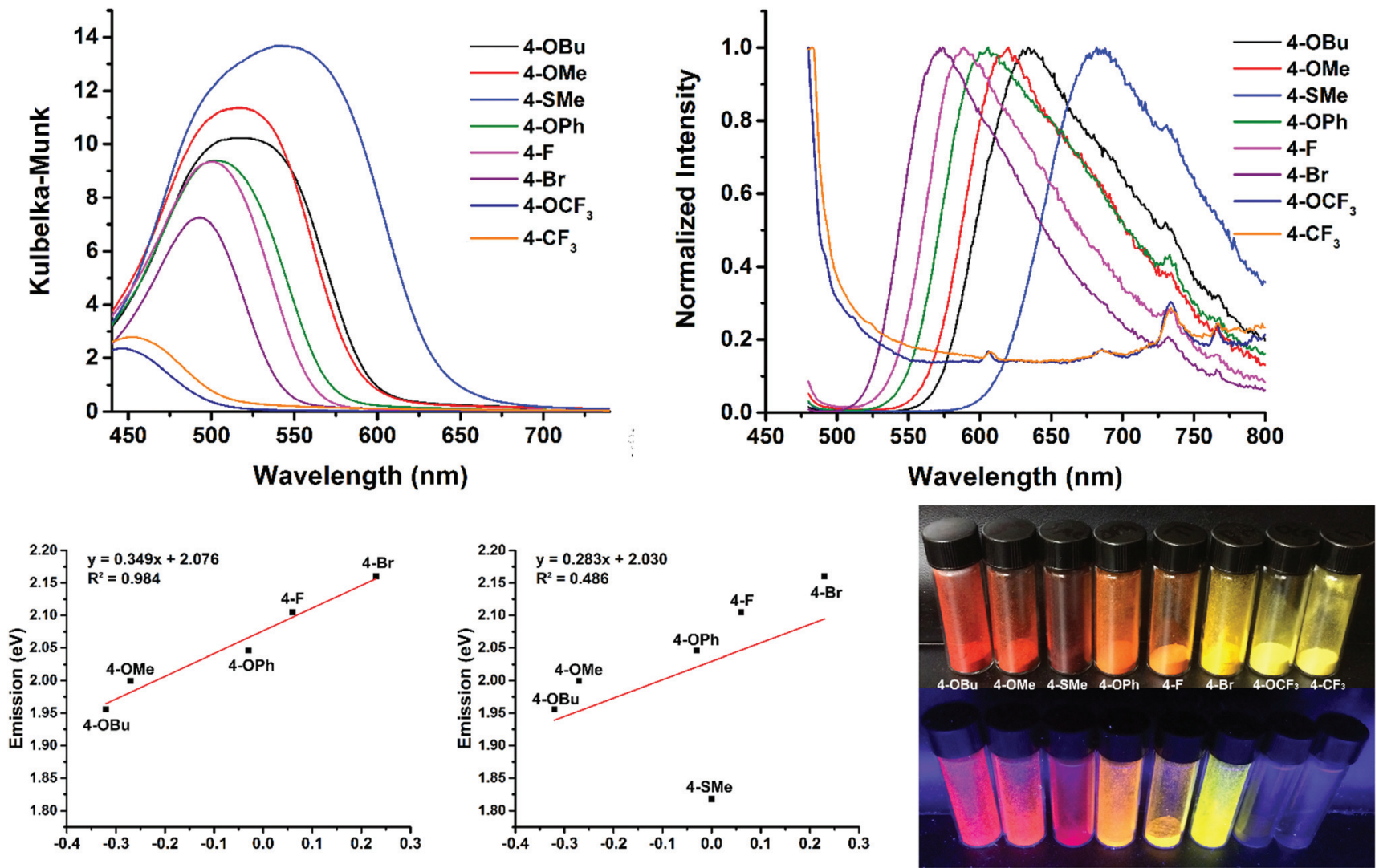

Fig. 3 (Top-Left) Solid state UV/Vis diffuse reflectance spectra for complexes 1-8. (Top-Right) Solid state emission spectra for complexes 1-8. (Bottom-Left) Hammett relationship between the $\sigma_{\mathrm{p}}$ value and the $\lambda_{\max }$ value in the absence of the 4-SMe outlier. (Bottom-Center) Hammett relationship between the $\lambda_{\max }$ and $\sigma_{\mathrm{p}}$ values including the 4-SMe outlier. (Bottom-Right) Photographs of complexes 1-8 in ambient light and under UV irradiation.

Table 3 Solid state emission data for complexes 1-8

\begin{tabular}{lllll}
\hline Complex & $\lambda_{\text {em }}(\mathrm{nm})$ & $\lambda_{\text {ex }}(\mathrm{nm})$ & $\tau(\mu \mathrm{s})$ & $\Phi(\%)$ (Absolute) \\
\hline $\mathbf{1}$ & 634 & 470 & $3.12 \pm 0.70$ & $1.06 \pm 0.09$ \\
$\mathbf{2}$ & 620 & 470 & $4.04 \pm 0.96$ & $1.20 \pm 0.05$ \\
$\mathbf{3}$ & 682 & 470 & $1.24 \pm 0.66$ & $1.33 \pm 0.18$ \\
$\mathbf{4}$ & 606 & 470 & $4.01 \pm 1.39$ & $1.30 \pm 0.08$ \\
$\mathbf{5}$ & 589 & 470 & $4.38 \pm 1.29$ & $1.72 \pm 0.03$ \\
$\mathbf{6}$ & 574 & 470 & $2.43 \pm 0.66$ & $1.80 \pm 0.06$ \\
7 & - & - & - & - \\
$\mathbf{8}$ & - & - & - & -
\end{tabular}

\section{Single crystal X-ray diffraction studies of 1-8}

Subsequent to probing the photophysical properties of each complex, the question that had arisen as to why complexes 7 and $\mathbf{8}$ were found to be nonemissive both in solution and also in the solid state remained unanswered. In our previous study involving methylated Ar-BIAN complexes, the nature of the solid state structure was found to have a strong influence on the emissive properties of each BIAN complex. ${ }^{17}$ The subsequent use of TD-DFT calculations revealed the existence of an intramolecular electron excitation that took place between the $\pi-\pi$ interactions of the two adjacent naphthalene units in

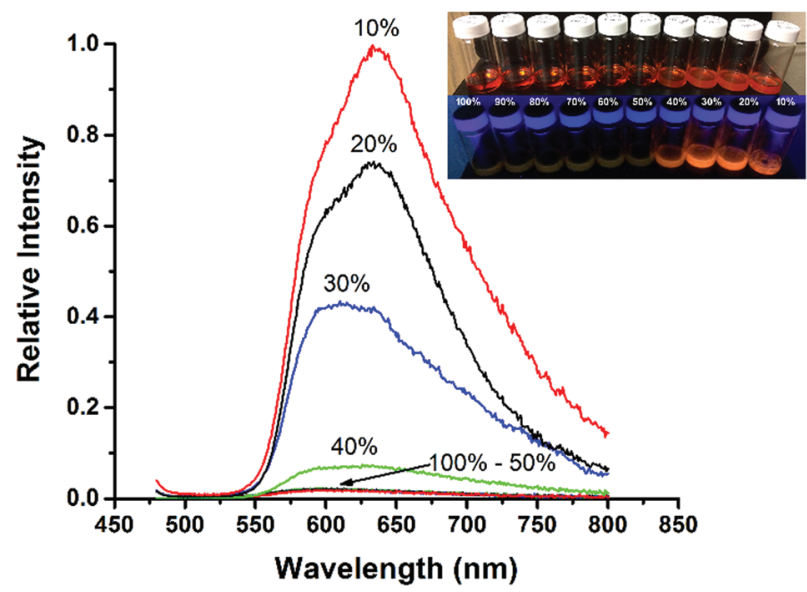

Fig. 4 AlE emission spectra and photographs of the DCM/hexanes volumetric fractions $\left(\sim 10^{-4} \mathrm{M}\right)$ of 1 (the above percentage values are relative to the DCM content).

the 4-Me BIAN zinc chloride complex. Furthermore, the transition density of this intermolecular excitation was used to visualize the $\mathrm{T}_{1} \rightarrow \mathrm{S}_{0}$ transition that was delocalized across an 
intermolecular $\pi-\pi$ stacked dimer. The nonemissive complexes that were investigated in our previous study did not feature this intramolecular arrangement in their crystal packing environments. Interestingly, our previous study was based on a steric congestion hypothesis, namely, that the ortho-substituted complexes inhibit the aforementioned intramolecular interactions due to steric repulsion. On the other hand, the less sterically bulky para- and meta-substituted complexes permit the foregoing intermolecular $\pi-\pi$ interactions. However, since complexes 1-8, feature very similar steric properties, this cannot be the factor that is responsible for the emissive/nonemissive behavior. Accordingly, it became necessary to conduct a thorough structural analysis of each complex in order to determine if structural differences were apparent between the emissive and nonemissive complexes in question.

Akin to the work described in our previous publication, ${ }^{17}$ recrystallization of this class of complexes was found to be particularly sensitive to the nature of the solvent that had been used for recrystallization. Fortunately, however, the crystalline powders that had precipitated directly from the acetic acid reaction mixture proved to be suitable for a series of single crystal X-ray diffraction experiments with complexes 1-8. The sole absence to this series was complex 6 . This omission is attributable to the fact that it was not possible to obtain a single crystal directly from the aforementioned precipitation reaction. Nevertheless, analysis of the "as-synthesized" crystalline powder of each complex provided a useful insight into the initial structure of each complex. However, since the "as-synthesized" crystalline powders could not be recrystallized for fear of altering their initial structures via solvatomorphism, the overall quality of the some of the structures was not high.

Despite the foregoing difficulties, the crystal structures of complexes 1-5 were studied and the results thereof are presented in Fig. 5. All five of these complexes exhibit a similar tetrahedral geometry with respect to the zinc metal center. However, complexes 2 and 3 both feature the presence of an acetic acid molecule in their respective lattice. On the other hand, complexes 1, 4, and 5 were found to be non-solvated. Surprisingly, structural analyses of the nonemissive complexes 7 and $\mathbf{8}$ led to the discovery that these complexes do not form analogous tetrahedral structures. Instead, these complexes each possess a dimeric bridging trigonal bipyramidal structure with respect to the zinc metal center.

As discussed in our previous publication, the packing environment of each BIAN Zn complex was found to have a significant impact on the emissive properties of the corresponding complex. ${ }^{17}$ Therefore, it is proposed that complexes $\mathbf{7}$ and $\mathbf{8}$ are nonemissive due to their different molecular geometries which in turn resulted in the formation of an overall different crystal packing environment.

In order to confirm the foregoing hypothesis, comparisons of the crystal packing environments of complexes 1-5 were made with those of 7 and 8. All five of these emissive complexes were found to possess crystal packing environments that were reminiscent of those that had been observed for the emissive BIAN complexes in our earlier study. ${ }^{17}$ Thus, each complex features a slipped stacked extended staircase array of intermolecular $\pi-\pi$ interactions between the adjacent naphthalene units. These staircase formations are attributable to the existence of close contacts that involve the chloride ligands on the zinc metal center in conjunction with both of the carbon atoms of the $\mathrm{N}-\mathrm{C}-\mathrm{C}-\mathrm{N}$ fragment and the naphthalenic hydrogen atoms. The representative packing diagram, exhibited in Fig. 5, clearly displays the staircase packing formation of complex 5. By contrast, the crystal packing environments of 7 and 8 do not feature slipped stacked staircase dimeric $\pi-\pi$ arrangements. Instead, each complex was found to exhibit infinite $\pi-\pi$ stacking in a columnar formation which can, in fact be a deleterious arrangement from the standpoint of emission. ${ }^{6}$

\section{Photophysical properties of the solvatomorphs of complexes 1-8}

Following the analysis of the "as-synthesized" crystalline powder samples (1-8), interest was generated in a solvatomorphic study. In our previous study, different recrystallization solvents had been employed in order to grow a series of solvatomorphs. Each solvatomorph included a different solvent molecule in the crystal lattice which in turn resulted in slight changes in the metrical parameters of the crystal packing. In each case, however, these slight modifications to the crystal packing environments resulted in significant changes in the solid state photoluminescent properties of each complex.

Given the foregoing result, a solvatomorphic study was performed using DCM as the recrystallization solvent, the objective being the formation of the DCM solvatomorphs of complexes 1-8. In each case, the solvatomorphs (1-DCM-8DCM) were grown by means of slow vapor diffusion of hexanes into a DCM solution. (It should be noted, however, that a different DCM solvatomorph of complex 2 had been reported previously. ${ }^{27}$ ) Each of the resulting solvatomorphs exhibited a tetrahedral molecular geometry with respect to the zinc metal center. Moreover, with the exception of the 4-F substituted complex, each of the complexes incorporated a DCM solvent molecule into the crystal lattice. Interestingly, recrystallization of the dimeric bridged trigonal bipyramidal complexes 7 and 8 resulted in the formation of the monomeric tetrahedral complexes that are displayed in Fig. 6.

Finally, the solid state photoluminescent properties of the DCM solvatomorphs were investigated. As displayed in Fig. 6 and Table 4, it was discovered that the emissive properties of complexes 1-DCM-4-DCM and 6-DCM displayed somewhat similar properties to those of the non-solvated crystalline powders, albeit in overall higher relative quantum yields $(\Phi)$. Surprisingly however, complex 5 failed to incorporate a DCM solvent molecule upon recrystallization, hence the photoluminescent properties remained unchanged. Interestingly however, the previously studied nonemissive complexes 7 and 8 were found to be emissive after recrystallization from DCM solution. This outcome is presumably a consequence of the formation of the slipped $\pi$-stacked staircase formations in the monomeric tetrahedral DCM solvatomorphs 7-DCM and 

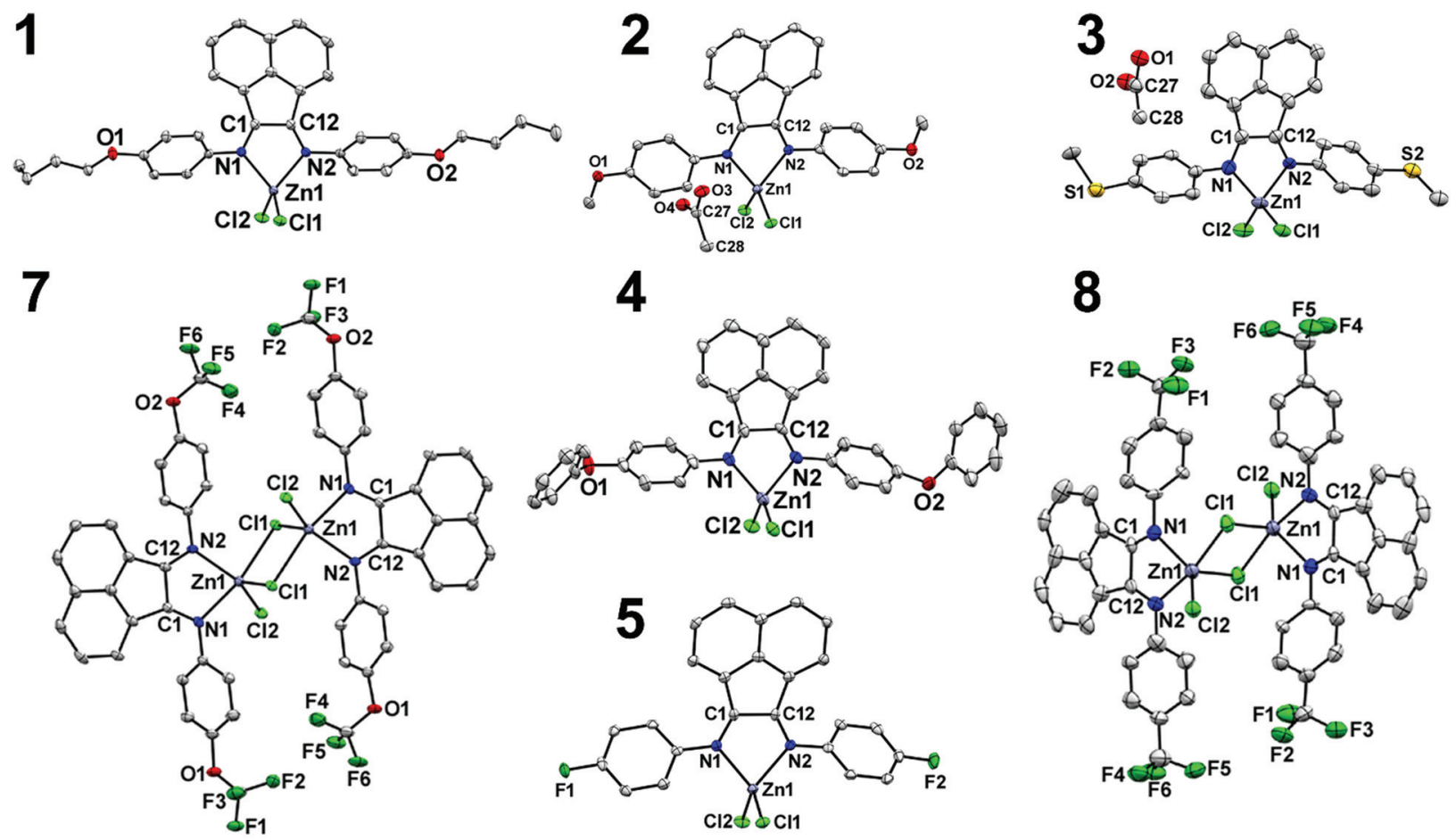

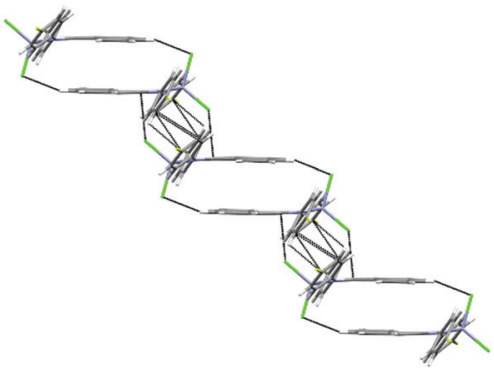

Packing for 5

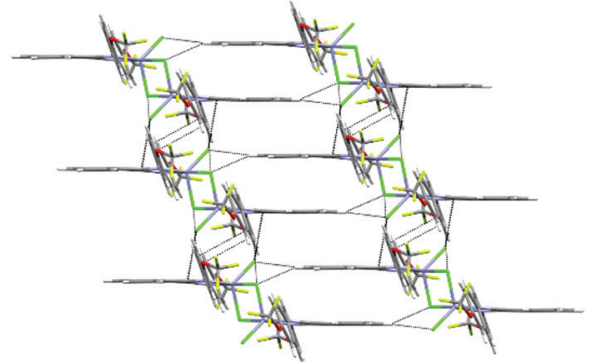

Packing for 7

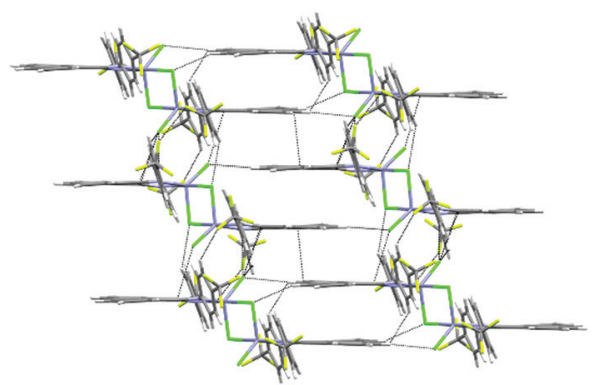

Packing for 8

Fig. 5 (Top) POV-Ray diagrams for complexes 1-5, 7 and 8 with thermal ellipsoids displayed at 50\% probability. All hydrogen atoms have been removed for clarity. Note however, that complexes 7 and 8 crystallized with only half of the dimeric complex in the asymmetric unit. The expanded complex is displayed for clarity. (Bottom) Representative packing diagrams for the emissive (5) and the nonemissive complexes (7 and 8 ) are also presented above.

8-DCM, both of which were absent in the respective "as-synthesized" crystalline lattices of 7 and $\mathbf{8}$

As evident from Fig. 6, the 4-F substituted complex failed to incorporate a DCM molecule into its crystal lattice upon recrystallization from DCM. Fortunately however, recrystallization of this complex from THF solution resulted in the isolation of a THF solvatomorph of complex 5. As displayed in Fig. 7, the incorporation of a THF molecule into the crystal lattice had a significant impact on the solid state emissive properties of the 4-F BIAN zinc chloride complex. The emission maximum for the THF solvatomorph $\mathbf{5}$ - THF was found to be blue shifted by approximately $30 \mathrm{~nm}$ in comparison with that of the non-solvated lattice of $\mathbf{5}$. Furthermore, the inclusion of a THF solvent molecule in the crystal lattice of 5-THF resulted in a change in the color of the emission from orange to yellow, as displayed in Fig. 7. The foregoing shift in the emission is presumably due to changes in both the molecular structure and the crystal packing environments of each solvatomorph. For example, the average torsion angle between the acenaphthene backbone and the flanking aryl rings of complexes 5 and 5-THF were found to be 53.88 and 65.21 degrees, respectively.

Overall, the differences in the emissive properties of the series of tetrahedral solvatomorphic Ar-BIAN zinc complexes can be best understood by inspection of the metrical parameters of the slipped stacked $\pi-\pi$ interactions due to the adjacent naphthalene backbones. The foregoing differences, all of which have been visualized and quantified, are listed in Table 5. Overall, the foregoing stacking interactions can be separated into four components, namely, the interplanar distance $(a)$, the slip distance between naphthalene centroids $(b)$, 

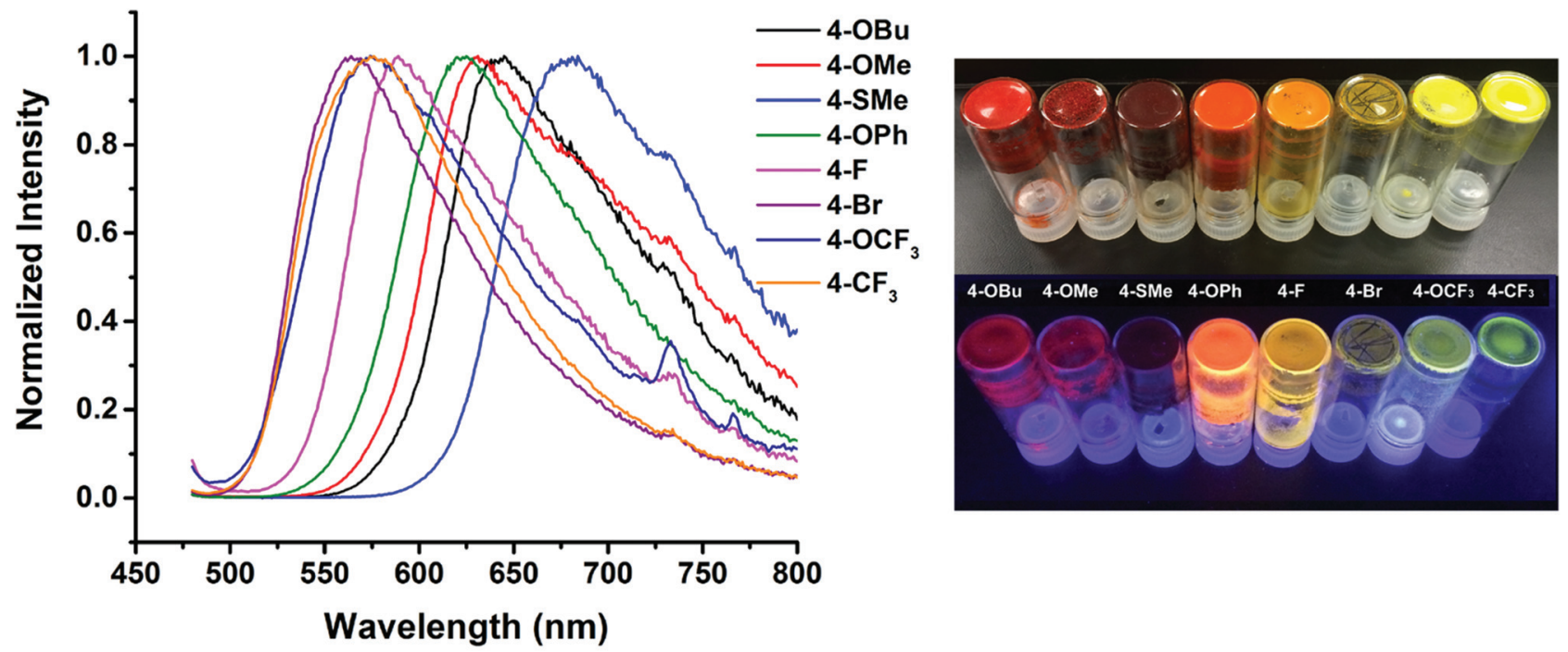

1-DCM

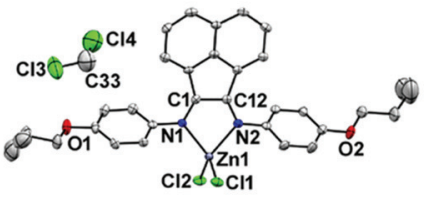

5

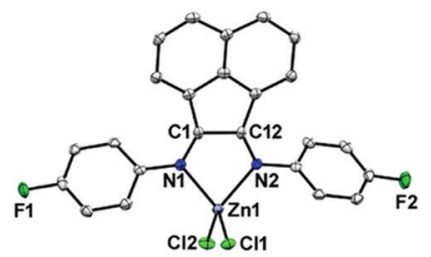

2-DCM

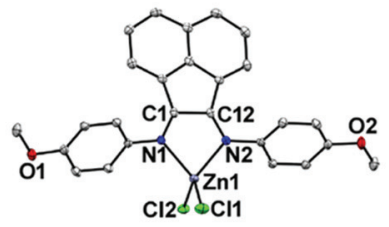

$\mathrm{Cl} 3 \stackrel{\mathrm{C} 27}{\mathrm{Cl} 4}$

6-DCM

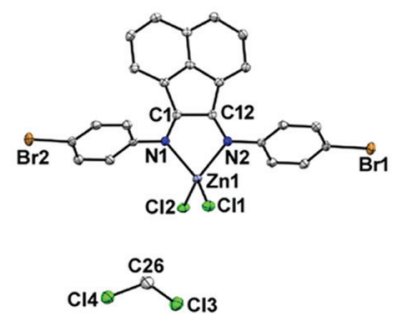

3-DCM

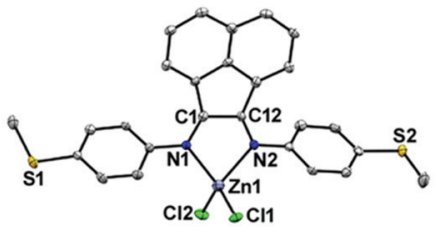

C13 ${ }^{\mathrm{C27}} \mathrm{Cl} 4$

7-DCM
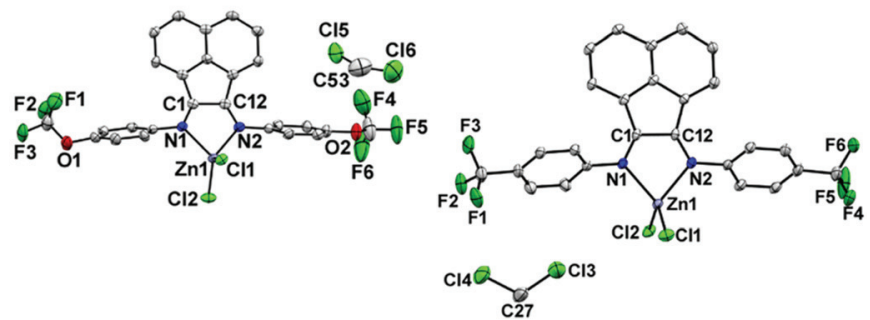

Fig. 6 (Top-Left) Solid state emission spectra for the DCM solvatomorphs 1-DCM-8-DCM (Top-Right). Photographs of all solvatomorphs under ambient light and UV irradiation. (Bottom) POV-Ray diagrams for solvatomorphs 1-DCM-8-DCM with thermal ellipsoids displayed at 50\% probability. All hydrogen atoms have been removed for clarity. Note however, that solvatomorph 7-DCM crystallized along with two BIAN complexes and two DCM solvent molecules in the asymmetric unit. Only one such complex is displayed in the interest of clarity.

Table 4 Solid state emission data for solvatomorphs of complexes 1-8

\begin{tabular}{lllll}
\hline Complex & $\lambda_{\text {em }}(\mathrm{nm})$ & $\lambda_{\text {ex }}(\mathrm{nm})$ & $\tau(\mu \mathrm{s})$ & $\Phi(\%)$ (Relative) \\
\hline 1-DCM & 645 & 470 & $5.13 \pm 1.87$ & $5.99 \pm 0.51$ \\
2-DCM & 631 & 470 & $3.06 \pm 1.06$ & $1.96 \pm 0.08$ \\
3-DCM & 684 & 470 & $3.58 \pm 1.46$ & $3.24 \pm 0.44$ \\
4-DCM & 625 & 470 & $1.60 \pm 0.57$ & $7.03 \pm 0.43$ \\
5-THF & 562 & 470 & $2.12 \pm 0.83$ & $2.89 \pm 0.05$ \\
6-DCM & 564 & 470 & $6.16 \pm 1.37$ & $2.57 \pm 0.09$ \\
7-DCM & 574 & 470 & $3.71 \pm 0.83$ & $1.80 \pm 0.06$ \\
8-DCM & 576 & 470 & $4.12 \pm 0.70$ & $9.54 \pm 0.32$
\end{tabular}

the distance between naphthalene centroids $(c)$, and the slip angle between naphthalene centroids $(\theta)$. The differences in stacking interactions were most obvious in the cases of complexes 5 and $\mathbf{5}$-THF, which resulted in a large shift in $\lambda_{\max }$ from orange to yellow, respectively.

\section{Computational study}

Time-dependent density functional theory calculations in the gas phase were carried in order to assess the ability of the substituents on the aryl groups to tune the electronic absorption spectra of the Ar-BIAN Zn complexes. The calculated parameters for the first prominent excitation $(f \geq 0.04)$ for com- 

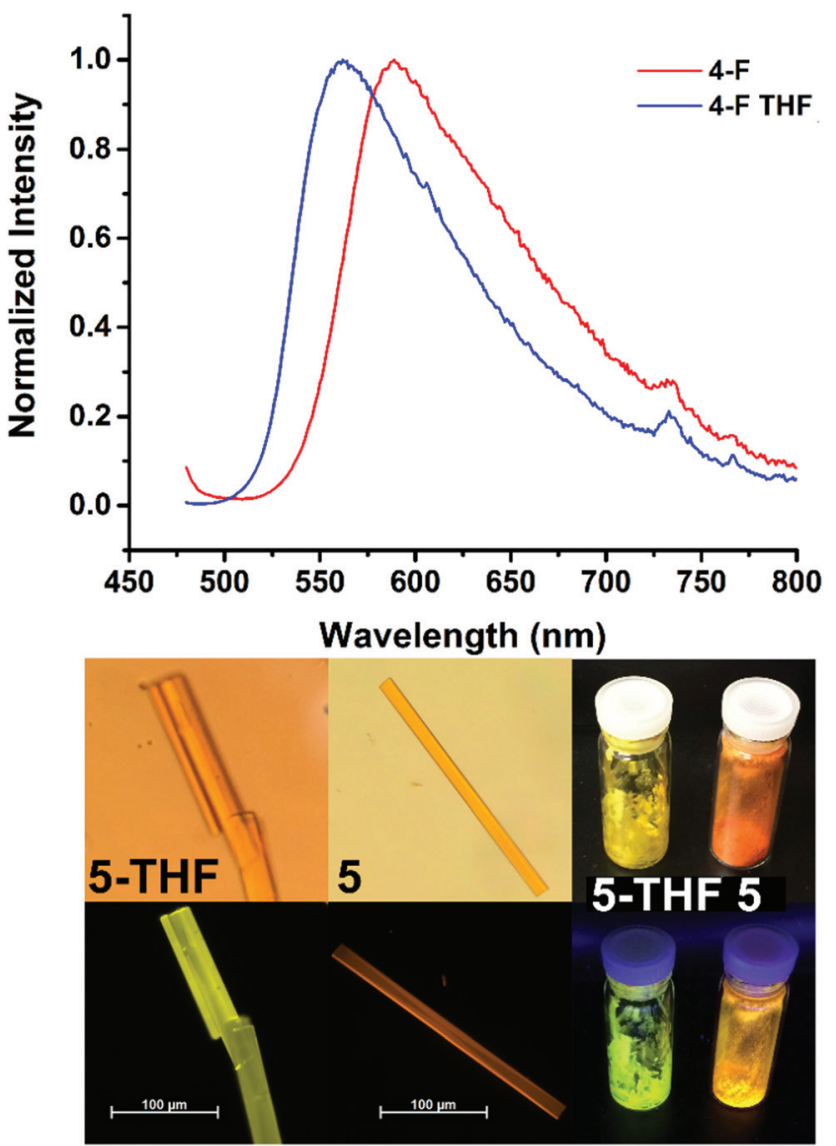

Fig. 7 (Right) Emission spectra for 5-THF and 5 with optical images displayed under ambient light and UV irradiation. (Left) Optical and fluorescent microscope images of 5-THF and 5.

Table 5 Calculated metrical parameters for the emissive tetrahedral complexes: $a=$ interplanar distance, $b=$ the slip distance between naphthalene centroids, $c=$ the distance between naphthalene centroids, $\theta=$ slip angle between naphthalene centroids

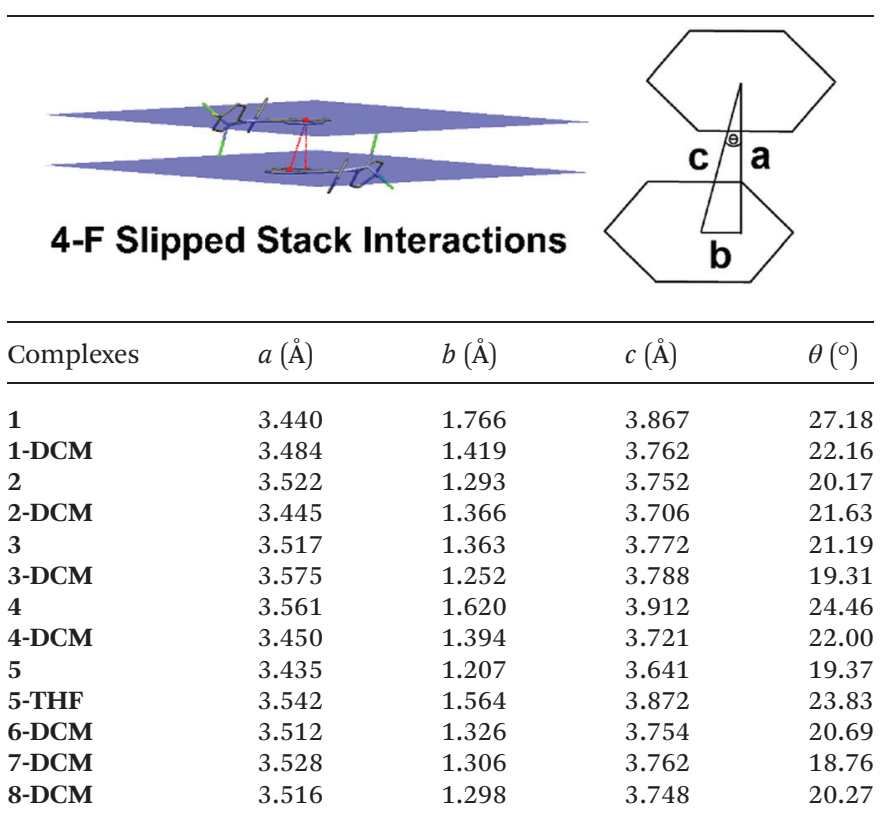

Table 6 Calculated parameters for the first prominent excitation ( $f \geq$ 0.04) for complexes $2,3,5,6$, and 8 . $\mathrm{H}=\mathrm{HOMO}, \mathrm{L}=\mathrm{LUMO}$

\begin{tabular}{|c|c|c|c|c|c|}
\hline \multicolumn{2}{|c|}{ Experimental } & \multicolumn{4}{|c|}{ Calculated } \\
\hline$R$ & $E(\mathrm{eV})$ & Rank & Assignment & $E(\mathrm{ev})$ & $f$ \\
\hline 4-OMe (2) & 2.59 & 1 & $\begin{array}{l}62 \% \mathrm{~L} \leftarrow \mathrm{H} \\
26 \% \mathrm{~L} \leftarrow \mathrm{H}-1\end{array}$ & 1.90 & 0.15 \\
\hline 4-SMe (3) & 2.50 & 1 & $95 \% \mathrm{~L} \leftarrow \mathrm{H}$ & 1.61 & 0.35 \\
\hline $4-\mathrm{F}(5)$ & 2.85 & 4 & $\begin{array}{l}36 \% \mathrm{~L} \leftarrow \mathrm{H}-1 \\
35 \% \mathrm{~L} \leftarrow \mathrm{H}-4 \\
27 \% \mathrm{~L} \leftarrow \mathrm{H}-2\end{array}$ & 2.09 & 0.07 \\
\hline & & 5 & $\begin{array}{l}53 \% \mathrm{~L} \leftarrow \mathrm{H}-4 \\
21 \% \mathrm{~L} \leftarrow \mathrm{H}-1 \\
11 \% \mathrm{~L} \leftarrow \mathrm{H}-2\end{array}$ & 2.24 & 0.07 \\
\hline $4-\operatorname{Br}(6)$ & 2.82 & 5 & $\begin{array}{l}47 \% \mathrm{~L} \leftarrow \mathrm{H}-4 \\
42 \% \mathrm{~L} \leftarrow \mathrm{H}-3\end{array}$ & 2.32 & 0.09 \\
\hline $4-\mathrm{CF}_{3}(8)$ & 2.90 & 4 & $\begin{array}{l}56 \% \mathrm{~L} \leftarrow \mathrm{H} \\
38 \% \mathrm{~L} \leftarrow \mathrm{H}-3\end{array}$ & 1.98 & 0.17 \\
\hline
\end{tabular}

plexes $\mathbf{2}, \mathbf{3}, \mathbf{5}, \mathbf{6}$, and $\mathbf{8}$ are presented in Table 6. (Note that only two excitations are presented for complex 5 due to the small energy separation and similar intensities). The calculated energies of the frontier orbitals of each model are presented in Fig. 8. Although this approximate method underestimates the excitation energies by as much as $0.90 \mathrm{eV}$, the order of the excitation energies is in agreement with the experimental observations and follows the trend of HOMO-LUMO gaps. However, in each case the calculated excitation energy is larger than the gap and the excitations are not simple two-orbital processes. As is typical for conjugated chromophores of this type, each excitation features multiple contributions. Nevertheless, in all

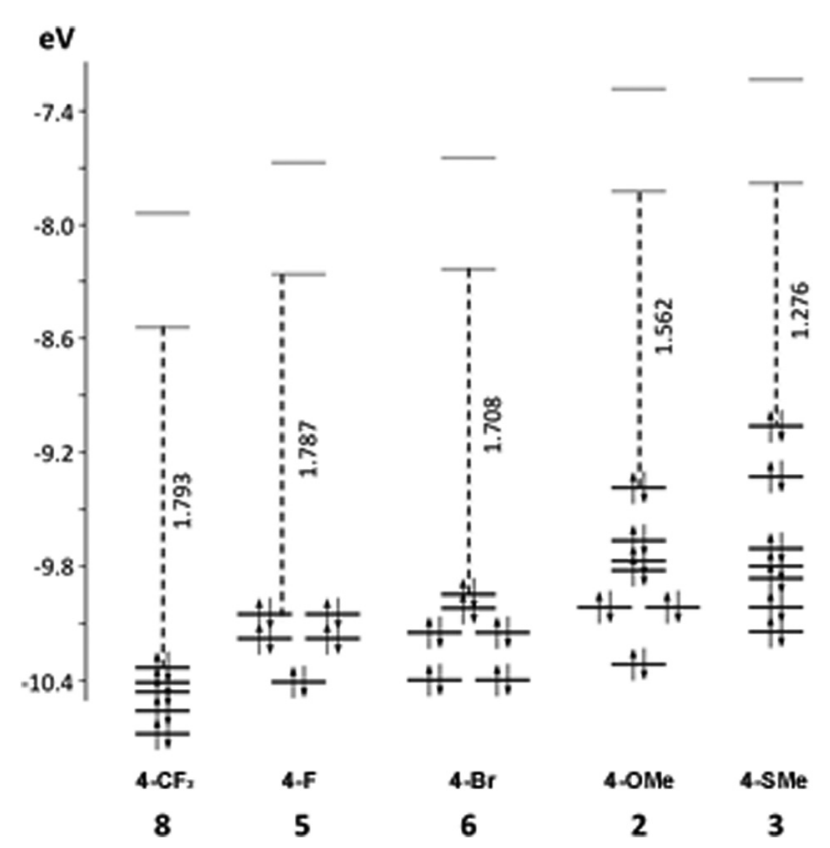

Fig. 8 Calculated frontier orbitals of selected Ar-BIAN Zn complexes. Pairs of orbitals that have similar energies are shown at the same height for clarity. However, no degeneracy is implied. 

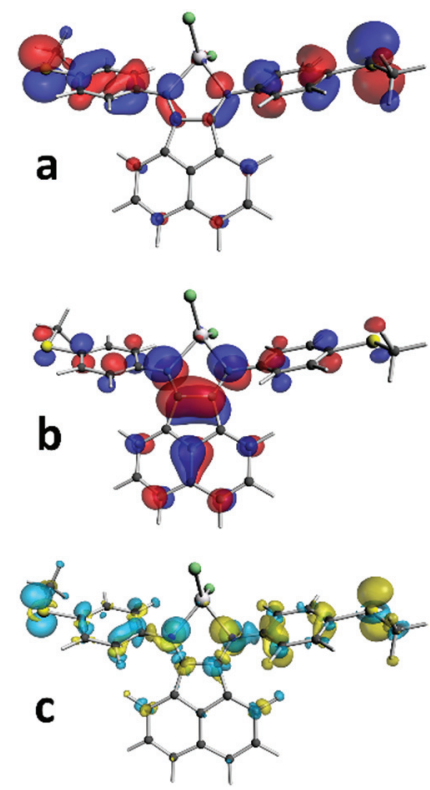

Fig. 9 Iso-surface plots of functions relevant to the first excitation of 3 . (a) HOMO (0.03 a.u.); (b) LUMO (0.03 a.u.); (c) transition density $\rho_{\text {ge }}(r)=$ $\psi_{\mathrm{g}}^{*}(r) \psi_{\mathrm{e}}(r)(0.0008$ a.u. $)$.

cases the absorption originates from the excitation of $\pi$ electrons from the phenyl rings into the LUMO, which predominantly contains contributions from the $\pi_{\mathrm{C}}^{*}=\mathrm{N}$ orbitals. This is easier to appreciate in the case of complex 3 , the only compound for which the HOMO-LUMO contribution to the first prominent excitation is $95 \%$. The composition of the frontier orbitals and the first transition density for this compound are displayed in Fig. 9. The substituents on the aromatic rings can influence such intramolecular charge transfers in two ways. The first way is inductive in nature. As the energy of the molecular orbitals decreases, the electron withdrawing ability of the substituents increases. The second effect is a decrease in the HOMO-LUMO gap that results from the interaction of electrons of the substituents with the $\pi$ manifold, which is noticeable in the composition of the HOMO of complex 3. It is the combination of these effects that places $\mathbf{8}$ and $\mathbf{3}$ at the extremes of the series.

\section{Conclusions}

In conclusion, the photophysical properties of eight para-substituted BIAN zinc chloride complexes have been examined. All eight complexes were found to be nonemissive in solution. However, it was discovered that complexes 1-6 exhibited color tunable solid state emissions that range from red-yellow. On the other hand, complexes 7 and 8 were found to be nonemissive in both the solid state and in solution. A detailed crystallographic study revealed the structural differences between the emissive complexes 1-6 versus those of the nonemissive complexes 7 and 8. The overall structural difference resulted in the formation of dissimilar crystal packing environments and hence different photophysical properties. Solvatomorphism was also investigated as a method to further tune the solid state emissions of complexes 1-8. Eight emissive solvatomorphic structures were grown and their photophysical properties were determined to be different in comparison with those of the "as-synthesized" complexes 1-8. Finally, a TD-DFT study was performed in order to gain further insight into the effects that the para-substituted flanking aryl substituents of the BIAN ligand had on the overall photophysical properties.

\section{Experimental}

\section{General procedures}

All reactions were performed in the ambient atmosphere with glassware that had been oven dried and flushed with argon gas prior to use. Each BIAN zinc complex was synthesized according to the pertinent literature procedures $\left(4-\mathrm{OMe},{ }^{18} 4\right.$ $\mathrm{F}^{19} 4-\mathrm{Br},{ }^{20}$ and $\left.4-\mathrm{CF}_{3}{ }^{21}\right)$. The $4-\mathrm{OBu}, 4-\mathrm{SMe}, 4-\mathrm{OPh}$, and 4 $\mathrm{OCF}_{3}$ substituted Ar-BIAN are new complexes that have not been reported previously.

\section{Physical measurements}

All NMR experiments were performed at $298 \mathrm{~K}$ on either a Varian DirectDrive instrument $\left({ }^{1} \mathrm{H}\right.$ NMR, $599.75 \mathrm{MHz} ;{ }^{13} \mathrm{C}$ NMR, $150.82 \mathrm{MHz})$, a Varian INOVA instrument $\left({ }^{1} \mathrm{H}\right.$ NMR, $499.87 \mathrm{MHz} ;{ }^{13} \mathrm{C}$ NMR, $125.71 \mathrm{MHz} ;{ }^{19} \mathrm{~F} 469.85 \mathrm{MHz}$ ), an Agilent MR instrument $\left({ }^{1} \mathrm{H}\right.$ NMR, $399.77 \mathrm{MHz} ;{ }^{13} \mathrm{C}$ NMR, $100.52 \mathrm{MHz} ;{ }^{19} \mathrm{~F} 469.85 \mathrm{MHz}$ ), or a Varian Unity Instrument $\left({ }^{1} \mathrm{H}\right.$ NMR, $399.14 \mathrm{MHz} ;{ }^{13} \mathrm{C}$ NMR, $\left.75.47 \mathrm{MHz} ;{ }^{19} \mathrm{~F} 282.41 \mathrm{MHz}\right)$ using residual solvent as the internal reference. The deuterated chloroform, dichloromethane, and dimethylsulfoxide solvents were purchased from Cambridge Isotopes Laboratories, Inc. and stored over $4 \AA$ molecular sieves prior to use. The highresolution chemical ionization mass spectral data (HRMS-CI) were acquired on a Micromass Autospec Ultima mass spectrometer. The melting points of 1-8 were determined using a Mel-Temp apparatus. Samples of complexes 1-8 were sent to Midwest Microlab, LLC for C, $\mathrm{H}$, and $\mathrm{N}$ elemental analyses.

\section{Fluorescence spectroscopy}

All solid state fluorescence spectroscopic data were collected on a Photon Technology International QM 4 spectrophotometer equipped with a 6-inch diameter K Sphere-B integrating sphere. The crystalline powders of 1-8 were loaded into quartz EPR tubes for measurement purposes and their chemical identities were confirmed by powder X-ray crystallography. All solvatomorph samples were loaded into quartz EPR tubes and subsequently covered with mineral oil in order to maintain crystallinity. The absolute quantum yield measurements were made by using a 6-inch diameter K Sphere-B integrating. sphere. The absolute quantum yield values were calculated by dividing the integrated area under each emission curve by the respective excitation peak of each sample. [(Area sample emission

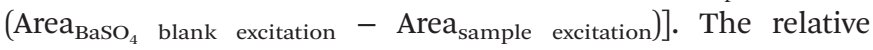


quantum yield values were calculated based on the ratio of the emission intensities. The intensity of the emission peak for each solvatomorph was integrated and compared with that of the non-solvated complex for which the absolute quantum yield had been measured directly. All graphs were constructed using the OriginPro 9.1 Student Version 64bit program.

\section{Single crystal X-ray crystallography}

In the cases of compounds $\mathbf{1 - 5 , 7}$, and $\mathbf{8}$, suitable single crystals could be obtained directly from each reaction mixture. Unfortunately, however, suitable single crystals of the as-synthesized complex 6 were not obtainable. Each solvatomorph crystal was grown from the appropriate solvent. In every case, the single crystals were removed from their respective vials, covered with mineral oil, and mounted separately on nylon thread loops. The X-ray diffraction data were collected on either an Agilent Technologies SuperNova Dual Source diffractometer using a $\mu$-focus $\mathrm{Cu} \mathrm{K} \alpha$ radiation source $(\lambda=1.5418 \AA)$ equipped with collimating mirror monochromators that operated at $147 \mathrm{~K}, 133 \mathrm{~K}$, or $100 \mathrm{~K}$, or on a Rigaku AFC12 Saturn $724+$ CCD diffractometer equipped with a Rigaku XStream low temperature device that operated at $100 \mathrm{~K}$, or on a Rigaku SCX-Mini diffractometer equipped with a Rigaku XStream low temperature device that operated at $153 \mathrm{~K}$. Both Rigaku instruments used a graphite-monochromated Mo Ko radiation source $(\lambda=0.71075 \AA)$. All powder X-ray diffraction data were collected on an Agilent Technologies SuperNova Dual Source diffractometer. Crystallographic details for all the structures can be found in the ESI. $\dagger$ Data collection, unit cell refinement, and data reduction were performed using the Agilent Technologies CrysAlisPro V 1.171.37.31 program. ${ }^{28}$ The structure of each complex was solved by direct methods and refined by full-matrix least squares on $F^{2}$ with anisotropic displacement parameters for all non-H atoms using SHELXL-2013 ${ }^{29}$ and PLATON98. ${ }^{30}$ All non-hydrogen atoms were refined anisotropically. The hydrogen atoms were placed in fixed, calculated positions with isotropic displacement parameters set at $1.2 \times$ $U_{\text {eq }}$ with respect to the attached atom $\left(1.5 \times U_{\text {eq }}\right.$ for methyl hydrogens). All powder XRD graphs were constructed using the OriginPro 9.1 Student Version 64 bit program. The POV-Ray images were created using the Mercury version 3.3 program and all the crystallographic details concerning the solvatomorph $\pi-\pi$ interactions were calculated using the Mercury version 3.3 program.

\section{Diffuse-reflectance and UV/Vis absorption spectroscopy}

All diffuse-reflectance measurements were performed with an illuminated (tungsten-halogen light source) integrating sphere (Ocean Optics ISP-REF) attached to a photodiode array spectrophotometer (Ocean Optics SD 2000) and all data are reported relative to a $\mathrm{BaSO}_{4}$ standard. Each measurement was integrated over $3 \mathrm{~ms}$ and corrected for stray light and dark current. The raw data were used to calculate the reflectance $(R)$ using Grams/AI (version 8.0). The Kubelka-Munk function $\left([1-R]^{2} / 2 R\right)$ was evaluated in Excel and the resulting spectra were smoothed by calculating the weighted averages of the values at neighboring points using the Cauchy density function as implemented within SigmaPlot (version 9). The final illustration was composed in PowerPoint. All UV/Vis absorption experiments were performed using a Varian Vary 6000i UV-VIS-NIR spectrophotometer and all UV/Vis graphs were constructed using the OriginPro 9.1 Student Version 64bit program.

\section{DFT calculations}

All DFT calculations were performed using the ADF DFT package (version 2013). ${ }^{31,32}$ Models of the complexes 2, 3, 5, 6, and 7 were built from their crystallographic coordinates and fully optimized using the exchange-correlation functional of Perdew, Burke, and Ernzerhof ${ }^{33}$ and corrected for dispersion ${ }^{34}$ with a triple- $\zeta$ all-electron basis set with two polarization functions and applying the Zeroth Order Regular Approximation (ZORA $)^{35-38}$ formalism with specially adapted basis sets. In the interest of expediency, the lowest 50 singlet-singlet electronic excitations ${ }^{39,40}$ were calculated using time-dependent density functional theory (TD-DFT) under the Statistical Average of different model Potentials for occupied KS Orbitals (SAOP). ${ }^{41-43}$

\section{Syntheses of 1-8}

4-Butoxyphenyl-BIAN zinc chloride (1). A mixture of acenaphthenequinone $(1.00 \mathrm{~g}, 5.49 \mathrm{mmol})$ and anhydrous zinc chloride $(2.02 \mathrm{~g}, 14.82 \mathrm{mmol})$ was suspended in $10 \mathrm{~mL}$ of glacial acetic acid, thereby generating a yellow suspension. The yellow suspension was heated to $60{ }^{\circ} \mathrm{C}$ and 4-butoxyaniline $(2.10 \mathrm{~mL}, 12.63 \mathrm{mmol})$ was added, following which the resulting solution was refluxed for 1 hour. The red precipitate that had formed during the reaction was filtered off and washed sequentially with water and diethyl ether. The resulting red crystalline powder was collected and used without further purification for a single crystal X-ray diffraction study $(2.94 \mathrm{~g}$, $88 \%)$.

HRMS (CI, $\mathrm{CH}_{4}$ ): calcd for $[\mathrm{M}-\mathrm{Cl}]^{+}\left[\mathrm{C}_{32} \mathrm{H}_{32} \mathrm{~N}_{2} \mathrm{O}_{2} \mathrm{ZnCl}\right]^{+} \mathrm{m} / \mathrm{z}$ 575.1444; found 575.1434; ${ }^{1} \mathrm{H}$ NMR $\left(\mathrm{CD}_{2} \mathrm{Cl}_{2}\right): \delta 1.023(\mathrm{t}, 6 \mathrm{H}$, $\left.\mathrm{CH}_{3}, J=7.4 \mathrm{~Hz}\right), 1.542\left(\mathrm{~m}, 4 \mathrm{H}, \mathrm{CH}_{2}\right), 1.840\left(\mathrm{~m}, 4 \mathrm{H}, \mathrm{CH}_{2}\right), 4.095$ $\left(\mathrm{t}, 4 \mathrm{H}, \mathrm{CH}_{2}, J=6.5 \mathrm{~Hz}\right), 7.122(\mathrm{~d}, 4 \mathrm{H}, \mathrm{Ar}-\mathrm{H}, J=9.0 \mathrm{~Hz}), 7.632$ (m, 6H, Ar-H) 7.844 (d, 2H, Ar-H, $J=7.4 \mathrm{~Hz}), 8.191$ (d, 2H, $\mathrm{Ar}-\mathrm{H}, J=7.8 \mathrm{~Hz}) .{ }^{13} \mathrm{C}$ NMR $\left(\mathrm{CD}_{2} \mathrm{Cl}_{2}\right): \delta 13.58,19.20,31.22$, $68.30,115.68,123.65,125.39,125.61,128.44,131.18,132.26$, 136.22, 144.62, 159.96, 161.41. Anal. Calcd for $\mathrm{C}_{32} \mathrm{H}_{32} \mathrm{~N}_{2} \mathrm{O}_{2} \mathrm{ZnCl}_{2}$ : C, 62.71; H, 5.26; N, 4.57. Found: C, 62.72; $\mathrm{H}, 5.24 ; \mathrm{N}, 4.62 . \mathrm{MP}=310^{\circ} \mathrm{C}$ (decomp).

4-Methoxyphenyl-BIAN zinc chloride (2). A mixture of acenaphthenequinone $(1.00 \mathrm{~g}, 5.49 \mathrm{mmol})$ and anhydrous zinc chloride $(2.02 \mathrm{~g}, 14.82 \mathrm{mmol})$ was suspended in $10 \mathrm{~mL}$ of glacial acetic acid, thereby generating a yellow suspension. The yellow suspension was heated to $60^{\circ} \mathrm{C}$ and $p$-anisidine $(1.55 \mathrm{~g}$, $12.63 \mathrm{mmol}$ ) was added, following which the resulting solution was refluxed for 1 hour. The red precipitate that had formed during the reaction was filtered off and washed sequentially with water and diethyl ether. The resulting red crystalline powder was collected and used without further puri- 
fication for a single crystal X-ray diffraction study (2.17 g, $75 \%)$.

HRMS (CI, $\mathrm{CH}_{4}$ ): calcd for $[\mathrm{M}-\mathrm{Cl}]^{+}\left[\mathrm{C}_{26} \mathrm{H}_{20} \mathrm{~N}_{2} \mathrm{O}_{2} \mathrm{ZnCl}\right]^{+} \mathrm{m} / \mathrm{z}$ 491.0505; found 491.0497; ${ }^{1} \mathrm{H}$ NMR $\left(\mathrm{CDCl}_{3}\right): \delta 3.923(\mathrm{~s}, 6 \mathrm{H}$, $\left.\mathrm{CH}_{3}\right), 7.095(\mathrm{~d}, 4 \mathrm{H}, \mathrm{Ar}-\mathrm{H}, J=6.8 \mathrm{~Hz}), 7.642(\mathrm{~m}, 6 \mathrm{H}, \mathrm{Ar}-\mathrm{H})$, 7.818 (d, 2H, Ar-H, $J=7.3 \mathrm{~Hz}$ ), 8.158 (d, 2H, Ar-H, $J=8.3 \mathrm{~Hz}$ ). ${ }^{13} \mathrm{C}$ NMR $\left(\mathrm{CDCl}_{3}\right): \delta 56.11,115.63,124.02,125.74,126.07$, $128.88,131.60,132.72,136.85,145.09,160.72,161.99$. Anal. Calcd for $\mathrm{C}_{26} \mathrm{H}_{20} \mathrm{~N}_{2} \mathrm{O}_{2} \mathrm{ZnCl}_{2} \cdot \mathrm{C}_{2} \mathrm{H}_{4} \mathrm{O}_{2}$ : C, $57.12 ; \mathrm{H}, 4.11 ; \mathrm{N}, 4.76$. Found: C, 57.19; H, 3.94; N, 4.67. $\mathrm{MP}=299^{\circ} \mathrm{C}$ (decomp).

4-(Methylthio)phenyl-BIAN zinc chloride (3). A mixture of acenaphthenequinone $(1.00 \mathrm{~g}, 5.49 \mathrm{mmol})$ and anhydrous zinc chloride $(2.02 \mathrm{~g}, 14.82 \mathrm{mmol})$ was suspended in $10 \mathrm{~mL}$ of glacial acetic acid, thereby generating a yellow suspension. The yellow suspension was heated to $60{ }^{\circ} \mathrm{C}$ and 4 -(methylthio) aniline $(1.57 \mathrm{~mL}, 12.63 \mathrm{mmol})$ was added, following which the resulting solution was refluxed for 1 hour. The dark red precipitate that had formed during the reaction was filtered off and washed sequentially with water and diethyl ether. The resulting dark red crystalline powder was collected and used without further purification for a single crystal X-ray diffraction study $(2.86 \mathrm{~g}, 93 \%)$.

HRMS (CI, $\mathrm{CH}_{4}$ ): calcd for $\left[\mathrm{M}-\mathrm{Cl}^{+}\left[\mathrm{C}_{26} \mathrm{H}_{20} \mathrm{~N}_{2} \mathrm{~S}_{2} \mathrm{ZnCl}\right]^{+} \mathrm{m} / \mathrm{z}\right.$ 523.0048; found 523.0032; ${ }^{1} \mathrm{H}$ NMR $\left(\mathrm{CDCl}_{3}\right): \delta 2.566(\mathrm{~s}, 6 \mathrm{H}$, $\left.\mathrm{CH}_{3}\right), 7.409(\mathrm{~d}, 2 \mathrm{H}, \mathrm{Ar}-\mathrm{H}, J=8.6 \mathrm{~Hz}), 7.580(\mathrm{~d}, 2 \mathrm{H}, \mathrm{Ar}-\mathrm{H}, J=$ $9.0 \mathrm{~Hz}), 7.628(\mathrm{t}, 2 \mathrm{H}, \mathrm{Ar}-\mathrm{H}, J=8.1 \mathrm{~Hz}), 7.409(\mathrm{~d}, 2 \mathrm{H}, \mathrm{Ar}-\mathrm{H}, J=$ $8.6 \mathrm{~Hz}), 8.158(\mathrm{~d}, 2 \mathrm{H}, \mathrm{Ar}-\mathrm{H}, J=8.6 \mathrm{~Hz}) .{ }^{13} \mathrm{C} \mathrm{NMR}\left(\mathrm{CDCl}_{3}\right)$ : $\delta$ 15.56, 122.56, 125.23, 125.94, 127.82, 128.66, 131.19, 132.48, 140.27, 140.75, 144.81, 161.72. Anal. Calcd for $\mathrm{C}_{26} \mathrm{H}_{20} \mathrm{~N}_{2} \mathrm{~S}_{2} \mathrm{ZnCl}_{2} \cdot \mathrm{C}_{2} \mathrm{H}_{4} \mathrm{O}_{2}$ : C, 54.16; H, 3.90; N, 4.51. Found: C, $54.22 ; \mathrm{H}, 3.75 ; \mathrm{N}, 4.80 . \mathrm{MP}=314^{\circ} \mathrm{C}$ (decomp).

4-Phenoxyphenyl-BIAN zinc chloride (4). A mixture of acenaphthenequinone $(1.00 \mathrm{~g}, 5.49 \mathrm{mmol})$ and anhydrous zinc chloride (2.02 g, $14.82 \mathrm{mmol})$ was suspended in $10 \mathrm{~mL}$ of glacial acetic acid, thereby generating a yellow suspension. The yellow suspension was heated to $60{ }^{\circ} \mathrm{C}$ and 4-phenoxyaniline $(2.34 \mathrm{~g}, 12.63 \mathrm{mmol})$ was added, following which the resulting solution was refluxed for 1 hour. The orange-red precipitate that had formed during the reaction was filtered off and washed sequentially with water and diethyl ether. The resulting orange-red crystalline powder was collected and used without further purification for a single crystal X-ray diffraction study $(2.41 \mathrm{~g}, 67 \%)$.

HRMS (CI, $\mathrm{CH}_{4}$ ): calcd for $[\mathrm{M}-\mathrm{Cl}]^{+}\left[\mathrm{C}_{36} \mathrm{H}_{24} \mathrm{~N}_{2} \mathrm{O}_{2} \mathrm{ZnCl}\right]^{+} \mathrm{m} / \mathrm{z}$ 615.0818; found 615.0816; ${ }^{1} \mathrm{H}$ NMR $\left(\mathrm{CDCl}_{3}\right): 7.196(\mathrm{~m}, 10 \mathrm{H}$, Ar-H) $7.432(\mathrm{t}-\mathrm{d}, 4 \mathrm{H}, \mathrm{Ar}-\mathrm{H}, J=7.1 \mathrm{~Hz}, J=1.8 \mathrm{~Hz}), 7.636(\mathrm{dd}$, $4 \mathrm{H}, \mathrm{Ar}-\mathrm{H}, J=6.8 \mathrm{~Hz}, J=2.2 \mathrm{~Hz}), 7.666(\mathrm{t}, 2 \mathrm{H}, \mathrm{Ar}-\mathrm{H}, J=7.8 \mathrm{~Hz})$, 7.773 (d, 2H, Ar-H, $J=7.1 \mathrm{~Hz}), 8.186$ (d, $2 \mathrm{H}, \mathrm{Ar}-\mathrm{H}, J=8.3 \mathrm{~Hz}$ ). ${ }^{13} \mathrm{C} \mathrm{NMR}\left(\mathrm{CDCl}_{3}\right): \delta 119.40,119.80,123.69,124.40,125.26$, 125.87, 128.65, 130.09, 131.23, 132.59, 138.20, 144.86, 156.02, 158.37, 161.83. Anal. Calcd for $\mathrm{C}_{36} \mathrm{H}_{24} \mathrm{~N}_{2} \mathrm{O}_{2} \mathrm{ZnCl}_{2}$ : C, 66.23; H, 3.71; N, 4.29. Found: C, 66.23; H, 3.61; N, 4.30. $\mathrm{MP}=316{ }^{\circ} \mathrm{C}$ (decomp).

4-Fluorophenyl-BIAN zinc chloride (5). A mixture of acenaphthenequinone $(1.00 \mathrm{~g}, 5.49 \mathrm{mmol})$ and anhydrous zinc chloride $(2.02 \mathrm{~g}, 14.82 \mathrm{mmol})$ was suspended in $10 \mathrm{~mL}$ of glacial acetic acid, thereby generating a yellow suspension. The yellow suspension was heated to $60{ }^{\circ} \mathrm{C}$ and 4 -fluoroaniline $(1.20 \mathrm{~mL}, 12.63 \mathrm{mmol})$ was added, following which the resulting solution was refluxed for 1 hour. The orange precipitate that had formed during the reaction was filtered off and washed sequentially with water and diethyl ether. The resulting orange crystalline powder was collected and used without further purification for a single crystal X-ray diffraction study $(2.33 \mathrm{~g}, 84 \%)$.

HRMS (CI, $\mathrm{CH}_{4}$ ): calcd for $[\mathrm{M}-\mathrm{Cl}]^{+}\left[\mathrm{C}_{24} \mathrm{H}_{14} \mathrm{~N}_{2} \mathrm{~F}_{2} \mathrm{ZnCl}\right]^{+} \mathrm{m} / \mathrm{z}$ 467.0105; found 467.012; ${ }^{1} \mathrm{H}$ NMR ( ${ }_{6}$-DMSO): $\delta 6.823(\mathrm{~d}, 2 \mathrm{H}$, $\mathrm{Ar}-\mathrm{H}, J=7.3 \mathrm{~Hz}), 7.141(\mathrm{~m}, 4 \mathrm{H}, \mathrm{Ar}-\mathrm{H}$, apparent complex coupling from fluorine), $7.360(\mathrm{~m}, 4 \mathrm{H}, \mathrm{Ar}-\mathrm{H}$, apparent complex coupling from fluorine), $7.559(\mathrm{t}, 2 \mathrm{H}, \mathrm{Ar}-\mathrm{H}, J=7.8 \mathrm{~Hz}), 8.115$ (d, $2 \mathrm{H}, \mathrm{Ar}-\mathrm{H}, J=8.3 \mathrm{~Hz}$ ). ${ }^{19} \mathrm{~F}$ NMR ( $\mathrm{D}_{6}$-DMSO): $\delta-119.83$ (m (apparent septet), Ar-F, 2F). ${ }^{13} \mathrm{C}$ NMR (D ${ }_{6}$-DMSO): $\delta 116.53$ (d, 4C, $J=22.54 \mathrm{~Hz}(\mathrm{~F})), 119.91,123.48,127.65,128.12,129.77$, 130.97, 141.17, 147.17, 159.60 (d, 2C, $J=240.19 \mathrm{~Hz}(\mathrm{~F})$ ), 160.70. Anal. Calcd for $\mathrm{C}_{24} \mathrm{H}_{14} \mathrm{~N}_{2} \mathrm{~F}_{2} \mathrm{ZnCl}_{2}$ : C, 57.12; H, 2.80; N, 5.55. Found: C, 56.83; H, 2.94; N, 5.44. $\mathrm{MP}=362{ }^{\circ} \mathrm{C}$ (decomp).

4-Bromophenyl-BIAN zinc chloride (6). A mixture of acenaphthenequinone $(1.00 \mathrm{~g}, 5.49 \mathrm{mmol})$ and anhydrous zinc chloride $(2.02 \mathrm{~g}, 14.82 \mathrm{mmol})$ was suspended in $10 \mathrm{~mL}$ of glacial acetic acid, thereby generating a yellow suspension. This yellow suspension was heated to $60{ }^{\circ} \mathrm{C}$ and 4-bromoaniline $(2.17 \mathrm{~g}, 12.63 \mathrm{mmol})$ was added, following which the resulting solution was refluxed for 1 hour. The dark yellow precipitate that had formed during the reaction was filtered off and washed sequentially with water and diethyl ether. The resulting dark yellow crystalline powder was collected and recrystallized from dichloromethane to obtain yellow crystals of 19. (2.92 g, 85\%).

HRMS (CI, $\mathrm{CH}_{4}$ ): calcd for $[\mathrm{M}-\mathrm{Cl}]^{+}\left[\mathrm{C}_{24} \mathrm{H}_{14} \mathrm{~N}_{2} \mathrm{Br}_{2} \mathrm{ZnCl}\right]^{+}$ $m / z$ 586.8504; found 586.8515; ${ }^{1} \mathrm{H}$ NMR ( $\mathrm{D}_{6}$-DMSO): $6.493(\mathrm{~d}$, $4 \mathrm{H}, \mathrm{Ar}-\mathrm{H}, J=6.7 \mathrm{~Hz}), 7.090(\mathrm{~d}, 4 \mathrm{H}, \mathrm{Ar}-\mathrm{H}, J=6.7 \mathrm{~Hz}), 7.886(\mathrm{t}$, $2 \mathrm{H}, \mathrm{Ar}-\mathrm{H}, J=7.5 \mathrm{~Hz}$ ), 8.043 (d, 2H, Ar-H, $J=7.0 \mathrm{~Hz}$ ), 8.401 (d, $2 \mathrm{H}, \mathrm{Ar}-\mathrm{H}, J=8.2 \mathrm{~Hz}$ ). ${ }^{13} \mathrm{C}$ NMR ( ${ }_{6}$-DMSO): $\delta 106.84,116.47$, 121.88, 129.01, 129.06, 130.92, 131.79, 132.91, 144.88, 148.17, 173.26. Anal. Calcd for $\mathrm{C}_{24} \mathrm{H}_{14} \mathrm{~N}_{2} \mathrm{Br}_{2} \mathrm{ZnCl}_{2}: \mathrm{C}, 46.01 ; \mathrm{H}, 2.25 ; \mathrm{N}$, 4.47. Found: $\mathrm{C}, 45.96 ; \mathrm{H}, 2.24 ; \mathrm{N}, 4.36 . \mathrm{MP}=352^{\circ} \mathrm{C}$ (decomp). 4-(Trifluoromethoxy)phenyl-BIAN zinc chloride (7). A mixture of acenaphthenequinone $(1.00 \mathrm{~g}, 5.49 \mathrm{mmol})$ and anhydrous zinc chloride $(2.02 \mathrm{~g}, 14.82 \mathrm{mmol})$ was suspended in $10 \mathrm{~mL}$ of glacial acetic acid, thereby generating a yellow suspension. The yellow suspension was heated to $60{ }^{\circ} \mathrm{C}$ and 4 -(trifluoromethoxy)aniline (1.69 mL, $12.63 \mathrm{mmol}$ ) was added, following which the resulting solution was refluxed for 1 hour. The yellow precipitate that had formed during the reaction was filtered off and washed sequentially with water and diethyl ether. The resulting yellow crystalline powder was collected and used without further purification for a single crystal X-ray diffraction study $(2.44 \mathrm{~g}, 70 \%)$.

HRMS (CI, $\mathrm{CH}_{4}$ ): calcd for [M - Cl] ${ }^{+}\left[\mathrm{C}_{26} \mathrm{H}_{14} \mathrm{~N}_{2} \mathrm{O}_{2} \mathrm{~F}_{6} \mathrm{ZnCl}\right]^{+}$ $m / z$ 598.9939; found 598.9929; ${ }^{1} \mathrm{H}$ NMR $\left(\mathrm{CDCl}_{3}\right): \delta 7.461(\mathrm{~d}$, $4 \mathrm{H}, \mathrm{Ar}-\mathrm{H}, J=8.3 \mathrm{~Hz}), 7.526(\mathrm{~d}, 2 \mathrm{H}, \mathrm{Ar}-\mathrm{H}, J=7.3 \mathrm{~Hz}), 7.669(\mathrm{~m}$, $6 \mathrm{H}, \mathrm{Ar}-\mathrm{H}), 8.228(\mathrm{~d}, 2 \mathrm{H}, \mathrm{Ar}-\mathrm{H}, J=8.3 \mathrm{~Hz}) .{ }^{19} \mathrm{~F} \mathrm{NMR}\left(\mathrm{CDCl}_{3}\right)$ : 
$\delta-58.18\left(\mathrm{~s},-\mathrm{OCF}_{3}, 6 \mathrm{~F}\right) .{ }^{13} \mathrm{C} \mathrm{NMR}\left(\mathrm{CDCl}_{3}\right): \delta 120.42$ (q, 2C, $\left.-\mathrm{CF}_{3}, J=258.2 \mathrm{~Hz}\right), 122.67,123.25,124.73,126.30,128.94$, 131.30, 133.06, 141.76, 145.42, 149.20, 163.02. Anal. Calcd for $\mathrm{C}_{26} \mathrm{H}_{14} \mathrm{~N}_{2} \mathrm{O}_{2} \mathrm{~F}_{6} \mathrm{ZnCl}_{2}$ : C, 49.05; H, 2.22; N, 4.40. Found: C, 49.40; H, 2.07; N, 4.39. $\mathrm{MP}=291{ }^{\circ} \mathrm{C}$ (decomp).

4-(Trifluoromethly)phenyl-BIAN zinc chloride (8). A mixture of acenaphthenequinone $(1.00 \mathrm{~g}, 5.49 \mathrm{mmol})$ and anhydrous zinc chloride $(2.02 \mathrm{~g}, 14.82 \mathrm{mmol}$ ) was suspended in $10 \mathrm{~mL}$ of glacial acetic acid and $2 \mathrm{~mL}$ of toluene, thereby generating a yellow suspension. The yellow suspension was heated to $60{ }^{\circ} \mathrm{C}$ and 4-(trifluoromethyl)aniline (1.59 $\mathrm{mL}, 12.63 \mathrm{mmol})$ was added, following which the resulting solution was refluxed for 1 hour. The yellow precipitate that had formed during the reaction was filtered off and washed sequentially with water and diethyl ether. The resulting yellow crystalline powder was collected and used without further purification for a single crystal X-ray diffraction study $(2.29 \mathrm{~g}, 69 \%)$.

HRMS (CI, $\mathrm{CH}_{4}$ ): calcd for $[\mathrm{M}-\mathrm{Cl}]^{+}\left[\mathrm{C}_{26} \mathrm{H}_{14} \mathrm{~N}_{2} \mathrm{~F}_{6} \mathrm{ZnCl}\right]^{+} \mathrm{m} / \mathrm{z}$ 567.0041; found 567.0046; ${ }^{1} \mathrm{H}$ NMR $\left(\mathrm{CD}_{2} \mathrm{Cl}_{2}\right): \delta 7.438(\mathrm{~d}, 2 \mathrm{H}$, $\mathrm{Ar}-\mathrm{H}, J=7.4 \mathrm{~Hz}), 7.679(\mathrm{t}, 2 \mathrm{H}, \mathrm{Ar}-\mathrm{H}, J=7.8 \mathrm{~Hz}), 7.732(\mathrm{~d}, 4 \mathrm{H}$, $\mathrm{Ar}-\mathrm{H}, J=8.2 \mathrm{~Hz}$ ), 7.935 (d, $4 \mathrm{H}, \mathrm{Ar}-\mathrm{H}, J=8.2 \mathrm{~Hz}), 8.259$ (d, 2H, $\mathrm{Ar}-\mathrm{H}, J=8.2 \mathrm{~Hz}) .{ }^{19} \mathrm{~F} \mathrm{NMR}\left(\mathrm{CD}_{2} \mathrm{Cl}_{2}\right): \delta-62.83(\mathrm{~s}, \mathrm{Ar}-\mathrm{F}, 6 \mathrm{~F}) \cdot{ }^{13} \mathrm{C}$ NMR $\left(\mathrm{CD}_{2} \mathrm{Cl}_{2}\right): \delta 122.27,124.24(\mathrm{q}, 2 \mathrm{C}, J=272.50 \mathrm{~Hz}(\mathrm{~F}))$, 124.88, 127.06, 128.03 (q, 4C, $J=4.14 \mathrm{~Hz}(\mathrm{~F})), 129.37,130.97$ (q, 2C, $J=33.60 \mathrm{~Hz}(\mathrm{~F})), 131.70,133.71,146.02,147.28,164.00$. Anal. Calcd for $\mathrm{C}_{26} \mathrm{H}_{14} \mathrm{~N}_{2} \mathrm{~F}_{6} \mathrm{ZnCl}_{2}$ : C, 51.64; H, 2.33; N, 4.63. Found: C, 52.04; H, 2.27; N, 4.64. $\mathrm{MP}=370{ }^{\circ} \mathrm{C}$ (decomp).

\section{Acknowledgements}

We thank the Robert A. Welch Foundation for the generous financial support (Grant F-0003) (A.H.C.) The support of Canada's Natural Sciences and Engineering Research Council is also gratefully acknowledged. Portions of this work were made possible by using the facilities of the Shared Hierarchical Academic Research Computing Network (SHARCNET: http://www.sharcnet.ca) and Compute/Calcul Canada.

\section{References}

1 H. Xu, R. Chen, Q. Sun, W. Lai, Q. Su, W. Huang and X. Liu, Chem. Soc. Rev., 2014, 43, 3259-3302.

2 V. A. Montes, R. Pohl, J. Shinar and P. Anzenbacher, Chem. - Eur. J., 2006, 12, 4523-4535.

3 R. Pohl, V. A. Montes, J. Shinar and P. Anzenbacher, J. Org. Chem., 2004, 69, 1723-1725.

4 S. Reineke, M. Thomschke, B. Lüssem and K. Leo, Rev. Mod. Phys., 2013, 85, 1245-1293.

5 S.-H. Yang, P.-J. Shih, W.-J. Wu and Y.-H. Huang, J. Lumin., 2013, 142, 86-91.

6 J. B. Birks, Photophysics of Aromatic Molecules, Wiley, London, 1970.
7 J. Luo, Z. Xie, J. W. Y. Lam, L. Cheng, H. Chen, C. Qiu, H. S. Kwok, X. Zhan, Y. Liu, D. Zhu and B. Z. Tang, Chem. Commun., 2001, 1740-1741.

8 Y. Hong, J. W. Y. Lam and B. Z. Tang, Chem. Soc. Rev., 2011, 40, 5361-5388.

9 J. Mei, Y. Hong, J. W. Y. Lam, A. Qin, Y. Tang and B. Z. Tang, Adv. Mater., 2014, 26, 5429-5479.

10 H. Tong, Y. Hong, Y. Dong, Y. Ren, M. Häussler, J. W. Y. Lam, K. S. Wong and B. Z. Tang, J. Phys. Chem. B, 2007, 111, 2000-2007.

11 K. Kokado and Y. Chujo, J. Org. Chem., 2011, 76, 316-319.

12 N. J. Hill, I. Vargas-Baca and A. H. Cowley, Dalton Trans., 2008, 240-253.

13 T. Kern, U. Monkowius, M. Zabel and G. Knör, Inorg. Chim. Acta, 2011, 374, 632-636.

14 C. J. Adams, N. Fey and J. A. Weinstein, Inorg. Chem., 2006, 45, 6105-6107.

15 C. J. Adams, N. Fey, Z. A. Harrison, I. V. Sazanovich, M. Towrie and J. A. Weinstein, Inorg. Chem., 2008, 47, 8242-8257.

16 S. K. Singh, S. K. Dubey, R. Pandey, L. Mishra, R.-Q. Zou, Q. Xu and D. S. Pandey, Polyhedron, 2008, 27, 28772882.

17 D. A. Evans, L. M. Lee, I. Vargas-Baca and A. H. Cowley, Organometallics, 2015, 34, 2422-2428.

18 F. Ragaini, S. Cenini and S. Tollari, J. Mol. Catal., 1993, 85, L1-L5.

19 J. W. Sprengers, M. de Greef, M. A. Duin and C. J. Elsevier, Eur. J. Inorg. Chem., 2003, 2003, 3811-3819.

20 G. Knör, M. Leirer, T. E. Keyes and J. G. Vos, Eur. J. Inorg. Chem., 2000, 2000, 749-751.

21 E. Shirakawa, H. Yoshida, Y. Nakao and T. Hiyama, J. Am. Chem. Soc., 1999, 121, 4290-4291.

22 R. van Asselt, C. J. Elsevier, W. J. Smeets, A. L. Spek and R. Benedix, Recl. Trav. Chim. Pays-Bas, 1994, 113, 88-98.

23 V. Rosa, T. Avilés, G. Aullon, B. Covelo and C. Lodeiro, Inorg. Chem., 2008, 47, 7734-7744.

24 A. Paulovicova, U. El-Ayaan, K. Shibayama, T. Morita and Y. Fukuda, Eur. J. Inorg. Chem., 2001, 2001, 2641-2646.

25 V. Rosa, C. I. M. Santos, R. Welter, G. Aullón, C. Lodeiro and T. Avilés, Inorg. Chem., 2010, 49, 8699-8708.

26 K. Hasan and E. Zysman-Colman, J. Phys. Org. Chem., 2013, 26, 274-279.

27 D. N. Coventry, A. S. Batsanov, A. E. Goeta, J. A. K. Howard and T. B. Marder, Polyhedron, 2004, 23, 2789-2795.

28 CrysAlisPro, version 1.171.37.31, Agilent Technologies UK Ltd., Oxford, UK, 2013.

29 G. M. Sheldrick, Acta Crystallogr., Sect. A: Fundam. Crystallogr., 2008, 64, 112-122.

30 A. L. Spek, Acta Crystallogr., Sect. A: Fundam. Crystallogr., 1990, 46, 34-34.

31 G. te Velde, F. M. Bickelhaupt, E. J. Baerends, C. Fonseca Guerra, S. J. A. van Gisbergen, J. G. Snijders and T. Ziegler, J. Comput. Chem., 2001, 22, 931-967.

32 C. F. Guerra, J. G. Snijders, G. te Velde and E. J. Baerends, Theor. Chem. Acc., 1998, 99, 391-403. 
33 J. P. Perdew, K. Burke and M. Ernzerhof, Phys. Rev. Lett., 1996, 77, 3865-3868.

34 S. Grimme, J. Comput. Chem., 2006, 27, 1787-1799.

35 E. van Lenthe, A. Ehlers and E. J. Baerends, J. Chem. Phys., 1999, 110, 8943-8953.

36 E. van Lenthe, E. J. Baerends and J. G. Snijders, J. Chem. Phys., 1993, 99, 4597-4610.

37 E. van Lenthe, E. J. Baerends and J. G. Snijders, J. Chem. Phys., 1994, 101, 9783-9792.

38 E. van Lenthe, J. G. Snijders and E. J. Baerends, J. Chem. Phys., 1996, 105, 6505-6516.
39 S. J. A. van Gisbergen, J. G. Snijders and E. J. Baerends, Comput. Phys. Commun., 1999, 118, 119-138.

40 A. Rosa, E. J. Baerends, S. J. A. van Gisbergen, E. van Lenthe, J. A. Groeneveld and J. G. Snijders, J. Am. Chem. Soc., 1999, 121, 10356-10365.

41 O. V. Gritsenko, P. R. T. Schipper and E. J. Baerends, Chem. Phys. Lett., 1999, 302, 199-207.

42 O. V. Gritsenko, P. R. T. Schipper and E. J. Baerends, Int. J. Quantum Chem., 2000, 76, 407-419.

43 P. R. T. Schipper, O. V. Gritsenko, S. J. A. van Gisbergen and E. J. Baerends, J. Chem. Phys., 2000, 112, 1344-1352. 